International Journal of Child, Youth and Family Studies (2018) 9(1): 121-131

DOI: http://dx.doi.org/10.18357/ijcyfs91201818123

\title{
RECONSIDERING RECENT DEVELOPMENTS IN JAPANESE RESIDENTIAL CARE AND THE ROAD TO FICE JAPAN
}

\author{
Shigeyuki Mori, Satoru Nishizawa, and Arimi Kimura
}

\begin{abstract}
In order to foster interactive discussions with other countries, this paper offers an overview of residential care for children in Japan and its ongoing development. Japan still relies especially heavily on the residential care system; this is due to the past process of development more than to traditional Japanese culture. The period from the post World War II era to the present is briefly described, including the rapid growth in the number of institutions before 1960, the rather stable period before 1990, the revision of the Child Welfare Act in 1997 permitting the privatization of institutions, and the movement towards problematizing child abuse in the mid 1990s, after which residential institutions were designated as the last resort for maltreated young people. In the present situation, smaller institutions and a foster care system are strongly promoted in accordance with international guidelines for alternative care and the recent governmental guideline based on the Child Rearing Vision of 2010 and the Child Welfare Act of 2016. The task of present Japanese residential care institutions is to realize a family-like environment and a better placement strategy, collaborate more with specialists to improve the standard of care, function in the community as centers for the care of children in need, and expand their care work for young adults and care leavers. The paper concludes by stressing the need for more international exchange among individuals and groups working in Japanese residential care.
\end{abstract}

Keywords: residential care, Japan, history, reformation process

Shigeyuki Mori is a professor in the Department of Human Sciences at Konan University, 8-9-1 Okamoto, Kobe, 658-8501, Japan. Email: moris@konan-u.ac.jp

Satoru Nishizawa is a professor in the Department of Social Work at Yamanashi Prefectural University, 5-11-1 Iida, Kofu, 400-0035, Japan. Email: nishizawa@yamanashi-ken.ac.jp

Arimi Kimura is a psychologist at a residential care institute, Koushou Gakuen, 9-1-1 Sinkotoni Shijou, Kitaku, Sapporo, 001-0904, Japan. Email: n.hata@kousyou.or.jp 
Japan is one of the very few developed countries where institutionalization is still the main option when protecting vulnerable children (Zhang, Fukui, \& Mori, 2016). Identifying the underlying reasons for this would involve multiple tasks, such as historical, sociological, economic, and cultural surveys, that are far beyond the scope of this paper. Here we aim only to give an overview of residential care for children in Japan and its ongoing development in order to develop interactive discussions with other countries and to form an international network, or at least start forming it, for future development. We will focus on the philosophy of the Japanese Child Welfare Act, as amended in 2016, in terms of its impact on the residential care system and practice.

\section{Reliance on Residential Care}

More than 46,000 children are in care in Japan, $88 \%$ of them in institutions (Ministry of Health, Labour and Welfare [MHLW], 2014). While foster care has been the major option for the care of children in need in many countries, Japan still relies heavily on the residential care system. Among developed countries, there is a wide range in the use of foster care, from strongly foster-care-oriented countries such as Australia and the United States to those at the other end of the scale, such as Israel and Germany, and Japan, with the least foster care of all (see Figure 1).

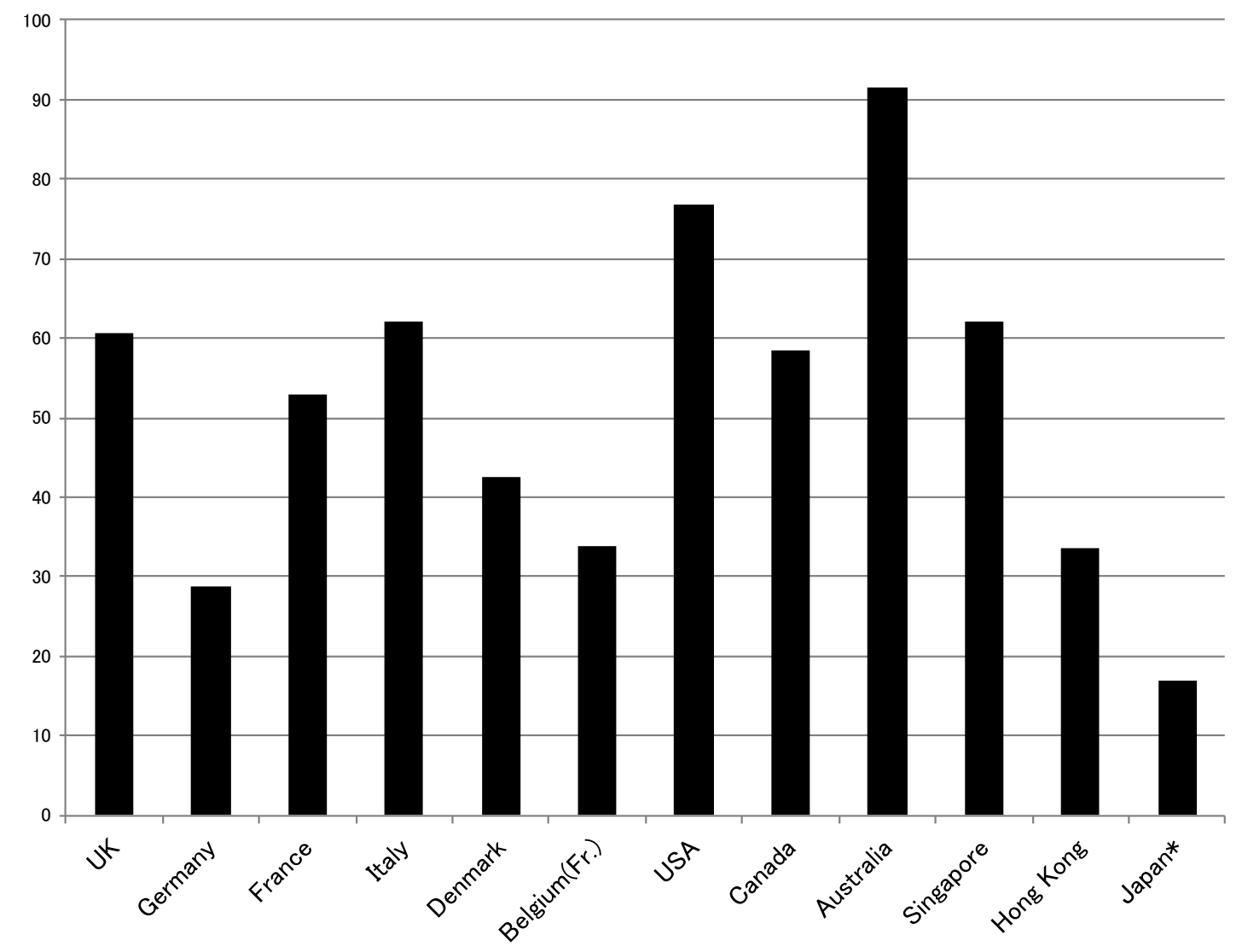

Figure 1. Ratio of foster care among children in care (MHLW, 2010).

* Japanese data from 2017 (MHLW, 2017). 
International Journal of Child, Youth and Family Studies (2018) 9(1): 121-131

No simple explanation for the underuse of foster care in Japan has yet been proposed. The "cultural explanation", which stresses traditional Japanese culture as a determinant of the family system and of the belief in the importance of blood relationships, is not well supported by research. Actually, foster family care was not foreign to Japanese families in the past: the shame associated with not living with biological parents, and the emphasis on blood relationships, which are regarded as having led to the dearth of foster family care, grew gradually along with the nuclearization of the family in the modern era (Goldfarb, 2012, 2018). Once in place, institutions change only subtly and gradually, resisting drastic transformation (Mahoney \& Thelen, 2009). Accounts of how institutions have been influenced by their preexisting forms of care accord with the theory of path dependency (Pierson, 2000; King, 2013), which explains a social status not from immanent causes, such as culture, but as a result of circumstantial reality with self-enforcing processes. This is supported by statistics that show a big difference in the foster care to residential care ratio among prefectures within Japan, although this may still be explained by cultural differences among the prefectures. Japanese culture is not as unified as is often supposed.

\section{Brief History of Japanese Residential Care Before the 21st Century}

The modern form of residential care was introduced into Japanese society in the $1890 \mathrm{~s}$, and the number of institutions grew significantly even before World War II. But the ground for today's residential care was set by a rapid expansion of care after the war to meet the needs of war orphans, and by the passage of the Child Welfare Act in 1947, which redefined orphanages as $Y \overline{o g} \bar{o}$ [rearing/caring] Shisetsu [institutions] (Goodman, 2000; Bamba \& Haight, 2011; Zhang et al., 2016). Following these developments, the number of institutions grew dramatically from 86 in 1945, to 306 in 1947, then 394 in 1950, and 528 in 1955. It was an era when residential care was still a standard form of alternative care throughout the world, and the government's policy of reliance on residential care to meet the needs of vulnerable children was not exceptional in the global context.

Subsequently the concepts of hospitalism and anaclitic depression (i.e., that institutionalization can have untoward physical and mental effects), which were taken up during and after the war (Bender \& Yarnell, 1941; Spitz, 1945, 1951; Bowlby, 1951), were introduced into Japanese practise in the 1950s and led to heated discussion. These concepts resulted in a shift to smaller-sized units in a limited number of institutions, with no change in the legally required standard of care. Notwithstanding the deinstitutionalizing shift since the 1950s in Western countries, especially English-speaking countries, no overall shift to foster care (i.e., deinstitutionalization), took place in Japan (Oda \& Ishii, 1982; Shōji et al., 2011). Although it is not easy to identify the reasons for this course of events, the fact remains that the government continued to prefer established institutions and did not support a systematic shift to foster care; this could perhaps be viewed as an example of path dependency. 
International Journal of Child, Youth and Family Studies (2018) 9(1): 121-131

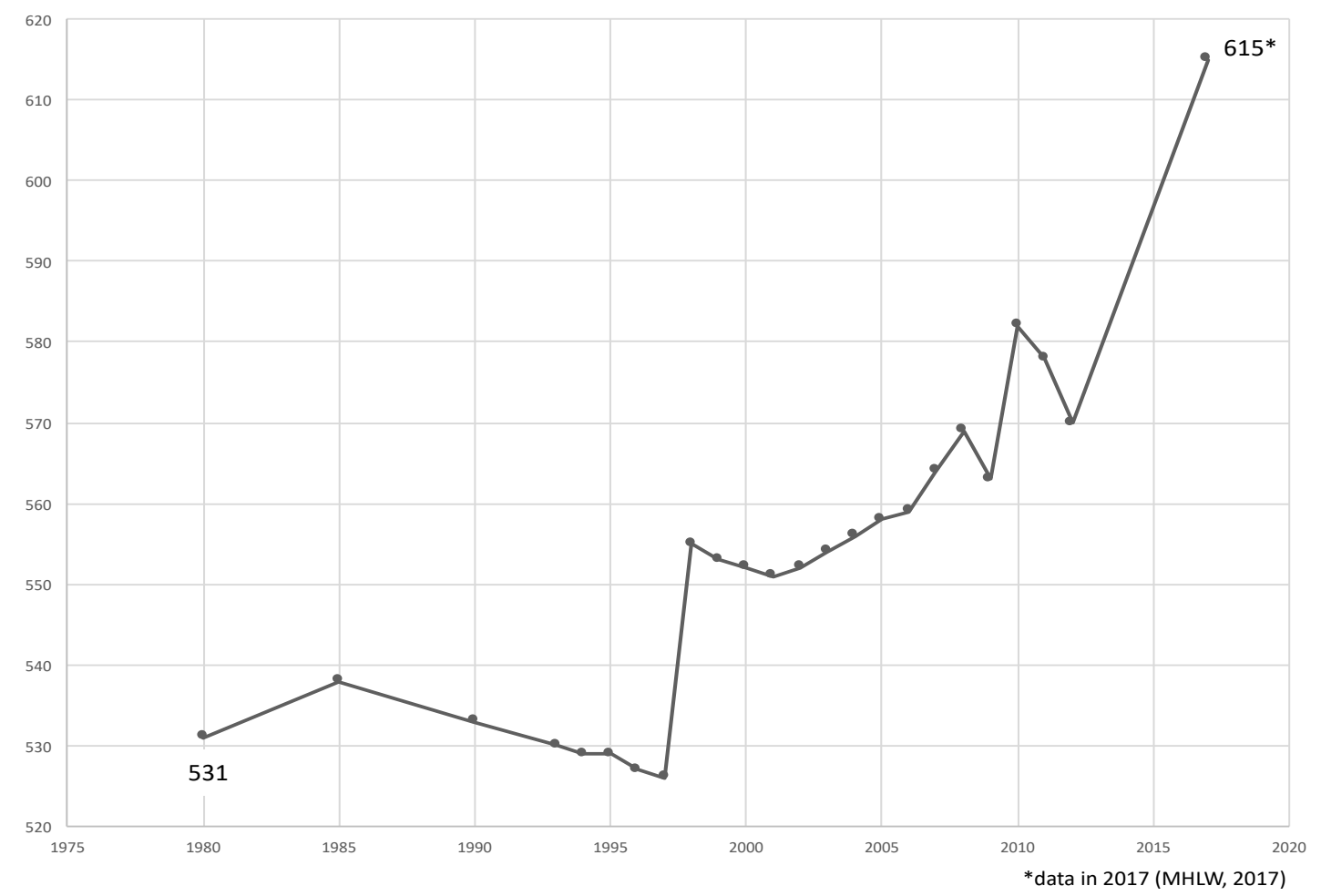

Figure 2. Number of institutions (Zenyokyo Zenkoku Jidouyōgoshisetu Kyogikai, 2018)

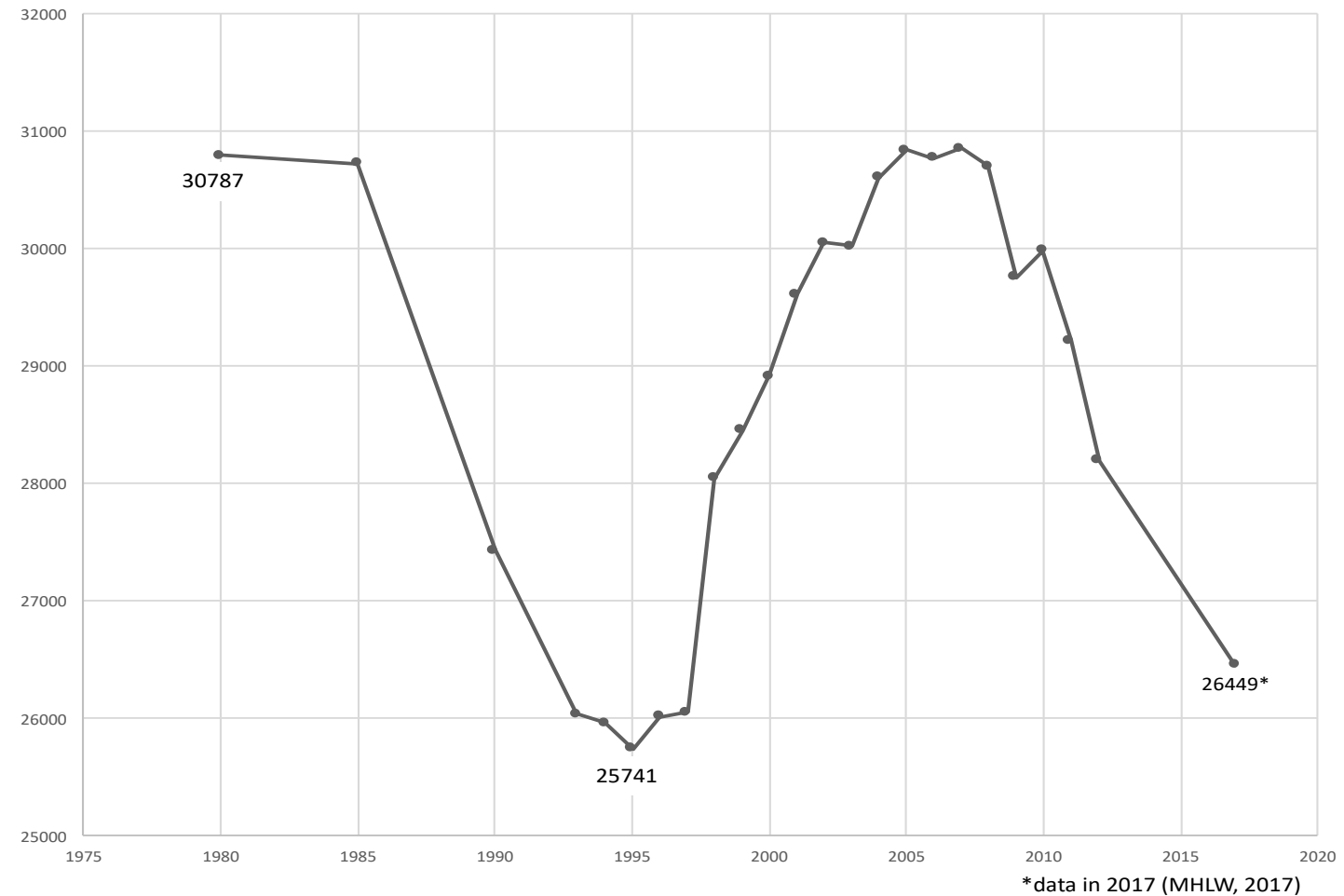

Figure 3. Number of children staying in institutions (Zenyokyo Zenkoku Jidouyōgoshisetu Kyogikai, 2018). 
International Journal of Child, Youth and Family Studies (2018) 9(1): 121-131

Circumstances surrounding residential care for children in Japan did not change, by and large, from the 1960s to the 1980s. After the rapid increase in the post-war era, the number of institutions stabilised at around 530, and the 1947 Act did not require any fundamental reformation of the system. The decade from the late 1980s was, in today's eyes, a calm period: the number of children staying in the institutions dropped dramatically, and when high economic growth allowed the majority of citizens to see themselves as belonging to the middle class, and reduced the number of children placed in care due to poverty. Directors worried that their institutions could not meet their quotas because of the shortage of children, and the number of institutions fell slightly (see Figures $2 \& 3$; the drop after 2005 in Figure 3 is due to an increase in foster care and new forms of residential care like group homes, which are not statistically included as institutions here).

In the meantime, the Child Welfare Act was undergoing amendment, and a new Child Welfare Act was enacted in 1997. The philosophy of the Act accorded with the international climate as well as with a trend in policy favoring privatization and consumer choice. The Act introduced a third-party evaluation system into the social welfare sector. Consumer choice was not introduced for residential care for children, however, and the primary goal of the amendment was to support youth to be independent by broadening the institutions' mandate beyond that of traditional "protection". The categorization of institutions was changed slightly, adding Jido [child] to make them Jidou Yōgo-Shisetsu, but this had no significant implications in terms of philosophy.

Around the same period, perhaps coincidentally, an unexpected change of circumstances took place: an increase in public attention given to child abuse under the impact of the ratification of the Convention of the Rights of the Child in1994. Media coverage of the ratification, and a rise in abuse-prevention activities by citizens' organizations, both contributed to the increase (The Child Abuse Prevention of the Whole Country Network, 2018). The heightened national focus on child abuse was also stimulated by the international child abuse prevention movement embodied in the International Society for the Prevention of Child Abuse and Neglect and its Japanese affiliate, the Japanese Society for the Prevention of Child Abuse and Neglect, which was established in 1994 as the Japanese Study Group for the Prevention of Child Abuse and Neglect and renamed in 2004 (Japanese Society for the Prevention of Child Abuse and Neglect, 2018).

That change brought the traditional "protection" function of institutions to the fore, and the number of children placed in institutions increased rapidly, as the Child Abuse Prevention Act of 2000 designated residential care institutions as virtually the only choice for alternative care of maltreated young people. At the same time, the changes led these institutions to broaden their scope, not only providing children with safe living spaces but also offering care and therapy to traumatized children, with special interest in their healthy development (Zhang et al., 2016). The concepts of trauma and attachment were introduced into the field by academics working for children's mental health, such as psychologists and psychiatrists, and these became the main 
International Journal of Child, Youth and Family Studies (2018) 9(1): 121-131

theoretical frameworks in working with children. These changes were exacerbated by the Great Hanshin-Awaji Earthquake in 1995 and the concomitant focus among mental health professionals on trauma.

Responding to the needs of overloaded institutions, local governments allocated some funding for additional staff, including psychotherapists, but institutions remained overloaded.

\section{Recent Developments: The 21st Century}

With the expanded task of protecting and caring for maltreated children on a large scale, there have been many arguments as to what residential care in Japan should be and what it should aim to accomplish. The past two decades in particular have seen a lot of discussions, planning, involvement, and change at both the governmental and non-governmental levels.

It has also been a period of pressure from international organizations such as the World Health Organization and UNICEF, as well as from academics, for more family-like settings (Zhang et al., 2016; Pinheiro, 2006; United Nations, 2010). The global shift to a policy of deinstitutionalization was reinforced by the issuing of Guidelines for the Alternative Care of Children by the United Nations (2010) based on the philosophy underlying the Convention on the Rights of the Child.

Responding to these pressures, the government formed working groups for the reformation of alternative care; these planned the functions not only of institutions but also of foster care under the total provisioning of an alternative care system (MHLW, 2007, 2011). In 2010, the government of Japan launched a program, Child Rearing Vision, that included goals to promote foster care and smaller-scale homes, though they were not the main thrust of the program. However, change did not come quickly. In 2014, a Human Rights Watch article sent a harsh message to Japan by including a figure showing that, as of 2011 , only $12 \%$ of children in alternative care were receiving foster care (Braunschweiger, 2014). In 2016, the section on alternative care in the Child Welfare Act was revised, with a clear description of the Rights of the Child, bringing hope that deinstitutionalization would soon follow.

As for non-governmental efforts at reform, three elements are worth mentioning: institutions' efforts to develop quality care, involvement of academics in residential care, and activities by academic societies.

\section{Institutions' Efforts to Develop Quality Care}

Institutions have been trying to meet these needs, conscious of both their heavy task and the expectations and criticisms from society. Some of them have introduced new forms of living space such as small-unit care (maximum 8 children) and group homes (maximum 6 children; Tables $1 \& 2$ ). Many have begun to either hire psychotherapists and psychiatrists or to work with them as outside supervisors. There have been many discussions in a variety of forms, from local 
International Journal of Child, Youth and Family Studies (2018) 9(1): 121-131

meetings to a national assembly of all the institutions. The overall quality of care has been improving, although outcomes vary across both institutions and locales.

Table 1 Children under each form of welfare service (MHLW, 2017)

\begin{tabular}{|c|c|c|}
\hline Service & $\begin{array}{l}\text { Number of } \\
\text { children }\end{array}$ & $\%$ \\
\hline Foster homes & 4578 & 9.9 \\
\hline Family homes & 829 & 1.8 \\
\hline Infant care institutions & 3069 & 6.7 \\
\hline Children's homes & 28831 & 62.6 \\
\hline Facilities for children with risk of delinquency & 1544 & 3.4 \\
\hline $\begin{array}{l}\text { Short-term treatment facilities for children with emotional } \\
\text { disturbances }\end{array}$ & 1310 & 2.8 \\
\hline Institutions for mothers in need of support & 5877 & 12.8 \\
\hline Total & 46038 & 100.0 \\
\hline
\end{tabular}

Table 2 The introduction of small group homes (MHLW, 2017)

\begin{tabular}{|c|c|c|c|c|c|c|c|c|}
\hline \multirow[b]{2}{*}{ Year } & \multirow[b]{2}{*}{$\begin{array}{l}\text { Number of } \\
\text { institutions }\end{array}$} & & \multicolumn{3}{|c|}{ Traditional homes } & \multicolumn{3}{|c|}{ Newly introduced small homes } \\
\hline & & & $\begin{array}{l}\text { Large } \\
(>20)\end{array}$ & $\begin{array}{l}\text { Medium } \\
(13-19)\end{array}$ & $\begin{array}{l}\text { Small } \\
(<12)\end{array}$ & $\begin{array}{l}\text { Small group } \\
\text { care homes }\end{array}$ & $\begin{array}{l}\text { Small homes } \\
\text { in community }\end{array}$ & $\begin{array}{c}\text { Other group } \\
\text { homes }\end{array}$ \\
\hline 2008 & 489 & $n$ & 370 & 95 & 114 & 212 & 111 & 55 \\
\hline 2000 & 489 & $\%$ & 75.8 & 19.5 & 23.4 & 43.4 & 22.7 & 11.3 \\
\hline 2012 & 561 & $n$ & 283 & 153 & 231 & 323 & 143 & 34 \\
\hline & & $\%$ & 50.4 & 27.3 & 41.2 & 57.6 & 25.5 & 6.1 \\
\hline
\end{tabular}

\section{Involvement of Academics in Residential Care}

As a result of the overreliance on institutions without a systematic procedure to include their practice within a local community, there was a lack of cooperation between institutions and other professional agencies. However, when the needs of children protected and placed after abuse became widely known in the 90s, practitioners and academics in child mental health and child development, such as psychologists, psychotherapists, psychiatrists, and pediatricians, gradually began to get involved in the field through supervising, intervention work, and research. This has resulted in a community of professionals who are willing to work in residential care. This resource is without doubt much stronger than it was a couple of decades ago.

\section{Activities by Academic Societies}

Organizational aspects of residential care work have undergone some development with the goal of integrating individual efforts. One example is the continual and sustained endeavor of a group of JaSPCAN members that has organized a number of sections at annual conferences. The Japanese affiliate of the World Association for Infant Mental Health is another important society that has contributed to the development of the field. Quite interestingly, a new society called Nihon Jido-Yogo Jissen Gakkai [The Japanese Society for Studies on Child Protective Care Practices] was established in 2009 for workers and professionals working with children at 
International Journal of Child, Youth and Family Studies (2018) 9(1): 121-131

residential care institutions. This is the harvest of discussions and efforts within institutions to meet present needs amid a deep awareness of changing requirements both inside and outside the field.

Despite these activities, we still lack a society for all the workers and professionals in which to discuss the full range of topics around residential care.

\section{The Present and the Future}

The present situation cannot be described without referring to the comprehensive revision of the Child Welfare Act that took place in 2016. It will result in regulation aimed at improving the ratio of children to workers, creating a family-like environment for children in care, and improving placement strategies. The promotion of foster care as a standard form of protecting and caring for maltreated children is a core policy of the Act, and the goal of establishing small group homes called "family homes", an expanded form of foster care, is an important aspect of that policy.

Under the Act, the function of residential care institutions will be expanded to respond to the needs not only of children in residential care, but also of children in the community, including those in foster care. The institutions are being designated as centers for the care of children in need, though much will need to be done to bring about their reformation and the adjustment of interactions between institutions and the community. To fulfill this assignment, it will be necessary to overcome the presumed prejudice towards children in care and care leavers, which is the counterpart of the shame associated with not living with biological parents. Social and school-based education about family diversity, abandoning the notion of a standard family type, will be helpful not only for children under institutional care but also those under foster care.

Another related issue that is being recognized, and that will be systematically addressed by the Act, is care work for young adults and care leavers. For Japanese residential care, which is regulated by the Child Welfare Act for children under 18 years, one area of concern has been how it can support care leavers over 18 years old. Institutions and workers with the volunteer spirit have been attempting to support them, but only with limited capacity, and without the benefits of a funded system. The new Act expands the possibility for care and support of young adults up to the age of 22 , when most university students graduate and get jobs; however, this is still limited compared with the practice in western countries such as the United Kingdom and Germany, where support continues up to 26 years of age.

In order to activate discussion and move towards an optimal system and quality practice, we need to open up the closed circle of Japanese residential care to the outside world, and encourage more international exchange among individuals and groups working in Japanese residential care. Japan has without a doubt suffered a "trade deficit" in such international exchange. Almost all the exchange has been learning and introducing western theories, practices, 
and systems into Japan, with little effort to communicate the Japanese experience to the outside world. In this regard, an exchange program between Japan and Thailand planned and managed by Jido-Yogo Jissen Gakkai (2014) is worthy of note.

\section{Conclusion}

We have presented an overview of Japanese residential care, including a brief history and a report on today's state of affairs. We have shown that the unique path of Japanese residential care for children has brought us to a transitional period where we have a chance to improve the quality of care and to address certain difficulties. What is clear is that we should not rely only on present resources that were developed separately as residential care and foster care along separate paths according to their individual needs and resources, but that we need a unified model of alternative care with collaboration between them. This will also require the collaboration of scholars and practitioners involved in the field according to their individual interests and needs.

In order to fulfill this complex task, we are planning to expand international exchange by joining FICE International and the CYC Network, which held their first joint congress in Vienna in 2016, where they presented their visions for expanding their network to the rest of the world, including African and Asian countries. The aim of this expansion will be not only to learn from the world, but also to examine the Japanese experience and inform the world of its strengths as well as its weaknesses. 
International Journal of Child, Youth and Family Studies (2018) 9(1): 121-131

\section{References}

Bamba, S., \& Haight, W. L. (2011). Child welfare and development: A Japanese case study. New York, NY: Cambridge University Press.

Bender, L., \& Yarnell, H. (1941). An observation nursery. American Journal of Psychiatry, 97, 1158-1174. doi:10.1176/ajp.97.5.1158

Bowlby, J. (1951). Maternal care and mental health. Geneva, Switzerland: World Health Organization.

Braunschweiger, A. (2014). Witness: Lack of support in Japanese orphanages. Retrieved from https://www.hrw.org/news/2014/05/01/witness-lack-support-japanese-orphanages

Goldfarb, K. (2012). Fragile kinships: Family ideologies and child welfare in Japan. Chicago, IL: University of Chicago, Division of the Social Sciences, Department of Anthropology.

Goldfarb, K. (2018, in press). Beyond blood ties: Intimate kinships in Japanese foster and adoptive care. In A. Alexy \& E. Cook (Eds.), Intimate Japan. Honolulu, HI: University of Hawaii Press.

Goodman, R. (2000). Children of the Japanese state: The changing role of child protection institutions in contemporary Japan. Oxford, UK: Oxford University Press.

Japanese Society for the Prevention of Child Abuse and Neglect. (2018). JaSPCAN towa [About JaSPCAN]. Retrieved from http://jaspcan.org/about

Jido-Yogo Jissen Gakkai [The Society for the Practice of Residential Care for Children]. (2014). Heisei 26 nen Taikokuseifu Shakaikaihatsu-ninngennhoshoushou Shakaifukushikyoku Rainichihoukoku [Report on the visit to Japan in 2014 by the Department of Social Development and Welfare, Ministry of Social Development and Human Security, Thailand]. Retrieved from http://yougojissen.jp/thailand_2.php

King, M. M. (2014). Stability and change in institutional alternative care for children in Israel and Japan. Better Care Network. Retrieved from https://bettercarenetwork.org/sites/default/files/attachments/Stability and Change in Institutional Alternative Care for Children in Israel and Japan.pdf

Mahoney, J., \& Thelen, K. (2009). A theory of gradual institutional change. In J. Mahoney \& K. Thelen (Eds.), Explaining institutional change: Ambiguity, agency, and power. Cambridge, UK: Cambridge University Press.

Ministry of Health, Labour and Welfare. (2014). Jidouyōgoshisetsu nyushojidoutou chousakekka [The result of a survey of children at residential care institutions for children]. Retrieved from http://www.mhlw.go.jp/bunya/kodomo/syakaiteki_yougo/dl/yougo_genjou_01.pdf 
International Journal of Child, Youth and Family Studies (2018) 9(1): 121-131

Ministry of Health, Labour and Welfare. (2017). Shakaitekiyōgo no genjou ni tsuite [About the actual status of the alternative care for children]. Retrieved from http://www.mhlw.go.jp/file/06-Seisakujouhou-11900000Koyoukintoujidoukateikyoku/0000187952.pdf

Oda, K., \& Ishii, I. (Eds.). (1982). Yōgo genri [Principles of protective care for children]. Kyoto, Japan: Minerva Shobo.

Pierson, P. (2000). Increasing returns, path dependence, and the study of politics. American Political Science Review, 94(2), 251-267. doi:10.2307/2586011

Pinheiro, P. S. (2006) World report on violence against children, UN Secretary-General's study on violence against children, United Nations, Geneva. Retrieved from http://www.unicef.org/violencestudy/5. World Report on Violence against Children.pdf

Shōji, J., Suzuki, T., \& Miyajima, K. (2011). Shakaitekiyōgo to sono Naiyou [State care and its contents]. Tokyo, Japan: Fukumura Shuppan.

Spitz, R. A. (1945). Hospitalism: An inquiry into the genesis of psychiatric conditions in early childhood. Psychoanalytic Study of the Child, 1, 53-74.

Spitz, R. A. (1951). The psychogenic diseases in infancy: An attempt at their etiologic classification. The Psychoanalytic Study of the Child, 6, 255-275. doi:10.1080/00797308.1952.11822915

The Child Abuse Prevention of the Whole Country Network. (2018). Jidougyakutai Boushihou Seido [Child abuse prevention law system]. Retrieved from http://www.orangeribbon.jp/about/child/institution.php

United Nations. (2010). Guidelines for the alternative care of children (General Assembly resolution A/RES/64/142). Retrieved from https://www.unicef.org/protection/alternative_care_Guidelines-English.pdf

Zenyokyo Zenkoku Jidouyōgoshisetu Kyogikai [The Council of Japanese Children's Homes]. (2018). Jidouyögoshisetsu no Gosyoukai [An overview of children's homes]. Retrieved from http://www.zenyokyo.gr.jp/what.htm

Zhang, Y., Fukui, Y., \& Mori, S. (2016). Japanese residential care in transformation: Implications and future directions. In T. Islam \& L. Fulcher (Eds.), Residential child and youth care in a developing world: Global perspectives (pp. 87-107). Retrieved from http://press.cyc-net.org/samples/Global Perspectives-ebook.pdf 